\title{
ERRATUM
}

\section{Application of emerging technologies to improve access to ischemic stroke care}

TO THE READERSHIP: An error appeared in the article by Vuong et al. (Vuong SM, Carroll CP, Tackla RD, et al: Application of emerging technologies to improve access to ischemic stroke care. Neurosurg Focus 42(4):E8, 2017).

Reference no. 10 was incorrect in the published article. The correct reference is shown below.

Carroll C, Tackla R, Vuong S, Jeong W, Serrone J, Ringer A: Robotic-assisted cerebral angiography and intracranial intervention: initial experience with the Magellan Catheter System. J Neurosurg 126:A1431, 2017 (Abstract)

The article has been corrected online as of May 2, 2017.

Andrew J. Ringer, MD

University of Cincinnati College of Medicine, Cincinnati, $\mathrm{OH}$

INCLUDE WHEN CITING

DOI: 10.3171/2017.4.FOCUS16520a.

CAANS, 2017 